\title{
Gan-Dan-Liang-Yi-Tang alleviates p-chlorophenylalanine-induced insomnia through modification of the serotonergic and immune system
}

\author{
YUAN HU, YU-NIN WANG, GANG-QIANG ZHANG, XIAN-ZHE DONG, WAN-WAN LIU and PING LIU \\ Department of Clinical Pharmacology and Pharmacy, Center of Pharmacy, \\ Chinese PLA General Hospital, Beijing 100853, P.R. China \\ Received February 17, 2015; Accepted July 13, 2016
}

DOI: $10.3892 / \mathrm{etm} .2016 .3737$

\begin{abstract}
Gan-Dan-Liang-Yi-Tang (GDLYT) is a Traditional Chinese Medicine that has been historically used for the treatment of insomnia. However, investigations into its pharmacological ingredients and the mechanism underlying its sedative and hypnotic effects remain limited. The present study reported the detailed mechanisms underlying the sedative and hypnotic effects of GDLYT. Kunming mice were administered GDLYT at various sub-hypnotic doses, which underwent sodium pentobarbital treatment test, pentetrazole induced convulsant studies and p-chlorophenylalanine (PCPA) induced insomnia model. Potentiated hypnotic and sedative effects in mice was studied, and also the changes in related neurotransmitter and immune factors were evaluated. The results suggested that GDLYT possessed weak sedative effects on pentetrazole-induced convulsive activity in normal mice at a dose of $1.3 \mathrm{mg} / \mathrm{kg}$, with an increase in sleep onset in subhypnotic dose of sodium pentobarbital-treated mice. GDLYT was also able to alleviate insomnia induced by PCPA in the rodent models, and increased 5-hydroxytryptamine levels in the prefrontal cortex, hippocampus, hypothalamus and corpus striatum of PCPA-treated rats. Furthermore, the hypnotic effects of GDLYT were modified, which allowed for PCPA-induced immune system changes, including increased interleukin (IL)-1 $\beta$, tumor necrosis factor- $\alpha$ and IL-2 expression levels. The results of the present study indicated that GDLYT induced sedative and hypnotic bioactivity by regulating serotonergic activity in the central nervous system and immune system.
\end{abstract}

Correspondence to: Dr Ping Liu, Department of Clinical Pharmacology and Pharmacy, Center of Pharmacy, Chinese PLA General Hospital, 23 Fuxing Road, Beijing 100853, P.R. China E-mail: liupingpla@126.com

Key words: gan-dan-liang-yi-tang, sedative-hypnotic effects, pentobarbital sleep, serotonergic system

\section{Introduction}

Gan-Dan-Liang-Yi-Tang (GDLYT) is a prescription drug used for the treatment of insomnia and terrified or sleepless, as described in the Chinese Traditional Medicine book "Bian-Zheng-Lu". GDLYT is composed of 3 ingredients: Yuan Zhi (Polygala tenuifolia), Bai Shao (Paeonia lactiflora Pall.) and Chao Zao Ren [Ziziphus jujuba Mill. var. spinosa (Bunge) Hu ex H. F. Chow]. Yuan Zhi has been used to treat insomnia, anxiety, restlessness and disorientation $(1,2)$. Polygalasaponins, the primary constituents of Yuan Zhi, are able to enhance pentobarbital-induced sleeping behaviors via $\gamma$-aminobutyric acid (GABA)-ergic systems in mice (3). Bai Shao, the processed root portion of Paeonia lactiflora Pall (Ranunculaceae), is a component of numerous Chinese medicinal formulae prescribed for the treatment of depression-like syndromes; Bai Shao functions by modifying the levels of serotonin [5-hydroxytryptamine (5-HT)] and its metabolite 5-hydroxyindoleacetic acid in the hippocampus (4-6). Chao Zao Ren has been reported to be a component of various Chinese Medicinal Herbs (7). Chao Zao Ren is able to improve sleep quality in patients and inhibit motion sickness effectively by reducing blood hormones levels in the hypothalamic-pituitary-adrenocortical axis (7-9).

Insomnia is a sleep disorder prevalent in women and the elderly (10). Currently, drugs used for the treatment of insomnia predominantly target the $\gamma$-aminobutyric acid (GABA) receptor, melatonin receptor, histamine receptor, orexin and serotonin receptor (10). Herbal medicine and Complementary and Alternative Medicine, such as Piper methysticum and the seed of Ziziphus jujuba Mill var. spinosa, have been widely used in phytotherapy for insomnia (11). GDLYT has been used for thousands of years as a Traditional Chinese Medicine; however, few studies have been conducted on its potential therapeutic effects in animal models. The present study investigated the sedative and hypnotic activities of GDLYT and explored the mechanisms underlying the sedative and hypnotic effects of GDLYT in various mouse models of insomnia. These effects were also investigated by analyzing monoamine neurotransmitters and inflammatory cytokines in the mouse models. 


\section{Materials and methods}

Extraction of GDLYT. Plant materials were purchased from Beijing Tong Ren Tang Medicinal Materials Co., Ltd. (Beijing, China) in October 2012. Shade-dried Yuan Zhi, Chao Zao Ren and Bai Shao were extracted 3 times with $\mathrm{H}_{2} \mathrm{O}$ for $1 \mathrm{~h}$ using a circumfluence extraction method, mixed with $50 \% \mathrm{EtOH}$, and the extracts were then filtered prior to the removal of $\mathrm{EtOH}$ insoluble parts. The soluble part was concentrated using a rotary vacuum evaporator. The residue was stored for 1 week at room temperature to obtain a dry solid mass.

Animals and ethical approval. A total of 420 Kunming mice weighing 20-24 g and 56 adult male Sprague-Dawley rats weighing 180-200 $\mathrm{g}$ were used for the behavioral experiments. All animals were obtained from the Animal Breeding Center of the PLA General Hospital (Beijing, China). The animals were housed in cages $(45 \times 60 \times 25 \mathrm{~cm})$ with water and food available ad libitum at a constant temperature $\left(22 \pm 2^{\circ} \mathrm{C}\right)$, under an 12-h light/dark cycle (lights on at 7:00). All animal experiments were carried out in accordance with the Principles of Laboratory Animal Care, the China legislation for the use and care of laboratory animals and the Institutional Animal Care and Use Committee of General Hospital of Chinese PLA.

Sub-hypnotic dosage of sodium pentobarbital treatment. Animals in the control and model groups were administered distilled water, while the drug treatment groups were administered sodium pentobarbital ( $1.3 \mathrm{mg} / \mathrm{kg} / \mathrm{day})$, and the animals in experimental groups were administered GDLYT at doses of $0.65,1.3,2.6$ and $5.2 \mathrm{~g} / \mathrm{kg} / \mathrm{day}$. Drugs were administered orally once daily for various durations, sodium pentobarbital i.p. $(25 \mathrm{mg} / \mathrm{kg})$ was carried on after $50 \mathrm{~min}$ of the last administration, the onset of sleep was observed in each mouse. Mice were considered to be asleep when they lost righting reflex for $>1$ min. In the sub-hypnotic dosage of sodium pentobarbital treatment test (12), the percentage of sleep onset was calculated as follows: Sleep onset $(\%)=($ No. falling asleep/total no.) $\mathrm{x} 100$.

Anticonvulsant experiments. The modified methods previously outlined by Chindo et al (13) and Ngo Bum et al (14) were used to estimate the anticonvulsant effect of GDLYT in mice. Briefly, the mice acclimatized to their new environment prior to the start of each experiment, and were kept in individual transparent mouse cages $(25 \times 15 \times 15 \mathrm{~cm})$ for $30 \mathrm{~min}$. Pentetrazole (PTZ; $100 \mathrm{mg} / \mathrm{kg}$ ) was used to induce convulsions (seizures) in the mice. Time latency between the administration of PTZ and myoclonic convulsive behavior was scored as follows: 0 , no response; 1 , ear and facial twitching; 2 , axial convulsive waves observed through the body; 3 , body jerks; 4 , generalized clonic convulsions with turning over into side position; 5 , generalized convulsions with tonic extension episodes and status epilepticus; 6 , mortality (15). Following an additional $30 \mathrm{~min}$, the lethality of treatment on the mice was recorded.

Parachlorophenylalanine (PCPA) pretreated model. For the PCPA pretreatment test, rats received intraperitoneal injec- tion of PCPA $(300 \mathrm{mg} / \mathrm{kg}$ ) between 08:00 and 09:00 once a day for 2 days. At 2 days after PCPA injection, GDLYT at various doses were administered for 7 days, observers were blinded to the treatment. Following PCPA injection, each mouse was observed and total movement distance was recorded, and rats were subsequently anesthetized by chloral hydrate $(350 \mathrm{mg} / \mathrm{kg})$ and sacrificed. The hippocampus, piriform cortex, hypothalamus, corpus striatum and brain stem were dissected from the brain on ice and the tissue samples were immediately immersed in liquid nitrogen and stored until further use.

Determination of 5-HT,NE and DA levels by high-performance liquid chromatography (HPLC). The level of 5-HT, NE and DA were determined by reverse-phase HPLC with electrochemical detection, as previously described (16). The 5-HT, DA and NE levels were determined as $\mathrm{mg} / \mathrm{g}$ wet weight tissue. Identification (by retention times) and content of the compounds (by peak areas) was determined in the tissue samples by comparing $0.2-4 \mathrm{ng} / \mathrm{ml} 5-\mathrm{HT}, \mathrm{NE}$ and DA standard solutions.

Serum cytokine measurements. Serum tumor necrosis factor (TNF)- $\alpha$, interleukin (IL)-1 $\beta$, IL-2, IL-4 and IL-6 concentrations were quantified by specific rat ELISA sandwich assays, performed using antibodies (R\&D Systems China Co. Ltd., Shanghai, China) according to the manufacturer's protocol. Absorbance was read at $450 \mathrm{~nm}$ on a microtitre plate reader (PerkinElmer, Inc., Waltham, MA, USA) and results were presented as $n g / l$ of serum.

Statistical analysis. The results are presented as means \pm standard error of the mean, indicating the number of animals per group for each experiment. Data were analyzed by one-way analysis of variance followed by Dunnett's post-hoc test for multiple comparisons. In a sub-hypnotic dosage of sodium pentobarbital treatment test, a $\chi^{2}$ test was used to compare number of mice that fell asleep. $\mathrm{P}<0.05$ was considered to indicate a statistically significant result.

\section{Results}

GDLYT induces hypnotic and sedative effects in mice. On the subhypnotic dosage of pentobarbital-treated mice, GDLYT raised the rate of sleep onset in 5 and 7 days with significant effects at 1.3 and $0.65 \mathrm{mg} / \mathrm{kg}(\mathrm{P}<0.01$; Table I). Following the PTZ-induced seizures experiment, GDLYT was observed to prolong the latency of convulsions in the treated groups after 5 and 7 days, as compared with the control group at $1.3 \mathrm{mg} / \mathrm{kg}$ doses and also protect against the mice mortality in 7 days $(\mathrm{P}<0.05$; Table II).

Effect of GDLYT on PCPA-induced insomnia in pentobarbital-treated mice. Consistent with the results of our previous unpublished study, the results of the present study indicated that treatment with PCPA $(300 \mathrm{mg} / \mathrm{kg}$ ) successfully induced insomnia. GDLYT significantly reversed the insomnia effects in PCPA-treated mice, by decreasing the total movement distance on days 2 and $7(\mathrm{P}<0.05$; Table III) compared with the PCPA mice. 
Table I. Effect of GDLYT on the sleep onset of mice treated with a sub-hypnotic dose of sodium pentobarbital $(\mathrm{n}=10-14)$.

\begin{tabular}{|c|c|c|c|c|c|c|c|}
\hline \multirow[b]{2}{*}{ Group } & \multirow[b]{2}{*}{$\begin{array}{l}\text { Dosage } \\
(\mathrm{g} / \mathrm{kg})\end{array}$} & \multicolumn{2}{|c|}{3 days } & \multicolumn{2}{|c|}{5 days } & \multicolumn{2}{|c|}{7 days } \\
\hline & & $\begin{array}{l}\text { No. of mice } \\
\text { asleep }(/ 10)\end{array}$ & $\begin{array}{c}\text { Sleep } \\
\text { onset }(\%)\end{array}$ & $\begin{array}{l}\text { No. of mice } \\
\text { asleep }(/ 10)\end{array}$ & $\begin{array}{c}\text { Sleep } \\
\text { onset }(\%)\end{array}$ & $\begin{array}{l}\text { No. of mice } \\
\text { asleep/total }\end{array}$ & $\begin{array}{c}\text { Sleep } \\
\text { onset }(\%)\end{array}$ \\
\hline Control & - & 1 & 10 & 1 & 10 & $1 / 12$ & 8 \\
\hline Diazepam & 0.0013 & 9 & $90^{\mathrm{a}}$ & 9 & $90^{\mathrm{a}}$ & $9 / 13$ & $69^{a}$ \\
\hline \multirow[t]{4}{*}{ GDLYT } & 5.2 & 3 & 30 & 4 & 40 & $4 / 13$ & 31 \\
\hline & 2.6 & 5 & 50 & 5 & 50 & $5 / 13$ & 31 \\
\hline & 1.3 & 5 & 50 & 6 & $60^{\mathrm{b}}$ & $7 / 11$ & 39 \\
\hline & 0.65 & 4 & 40 & 4 & 40 & $4 / 14$ & $64^{a}$ \\
\hline
\end{tabular}

${ }^{\mathrm{a}} \mathrm{P}<0.01$ and ${ }^{\mathrm{b}} \mathrm{P}<0.05$, vs. the control group. GDLYT, Gan-Dan-Liang-Yi-Tan.

A

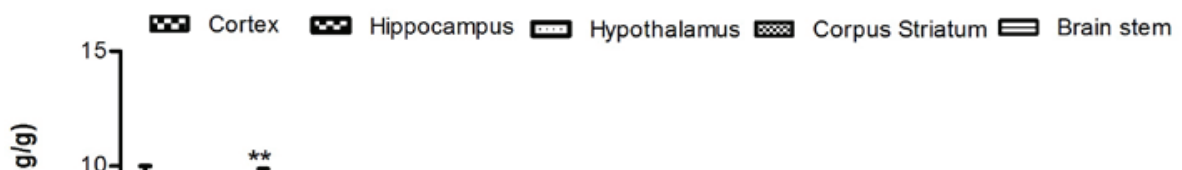
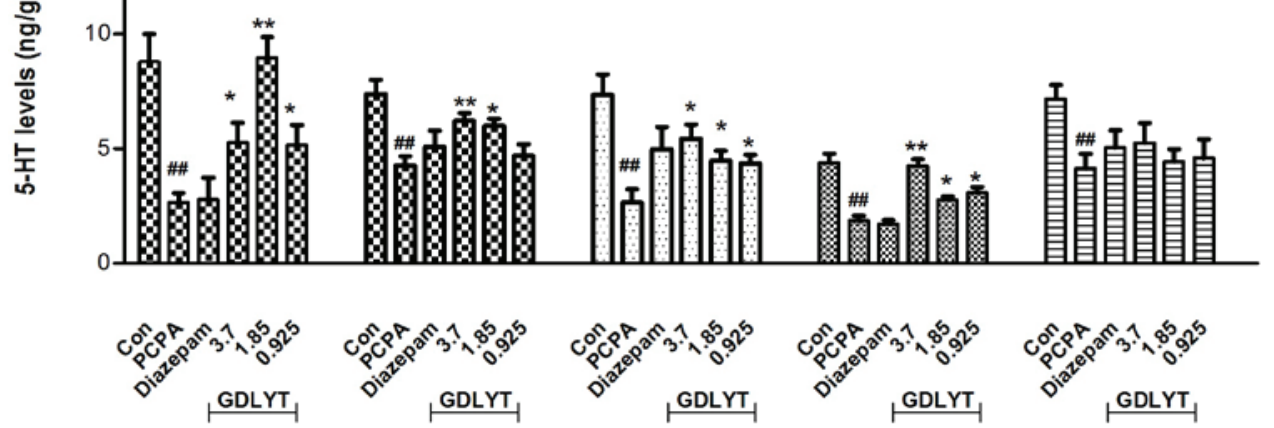

B

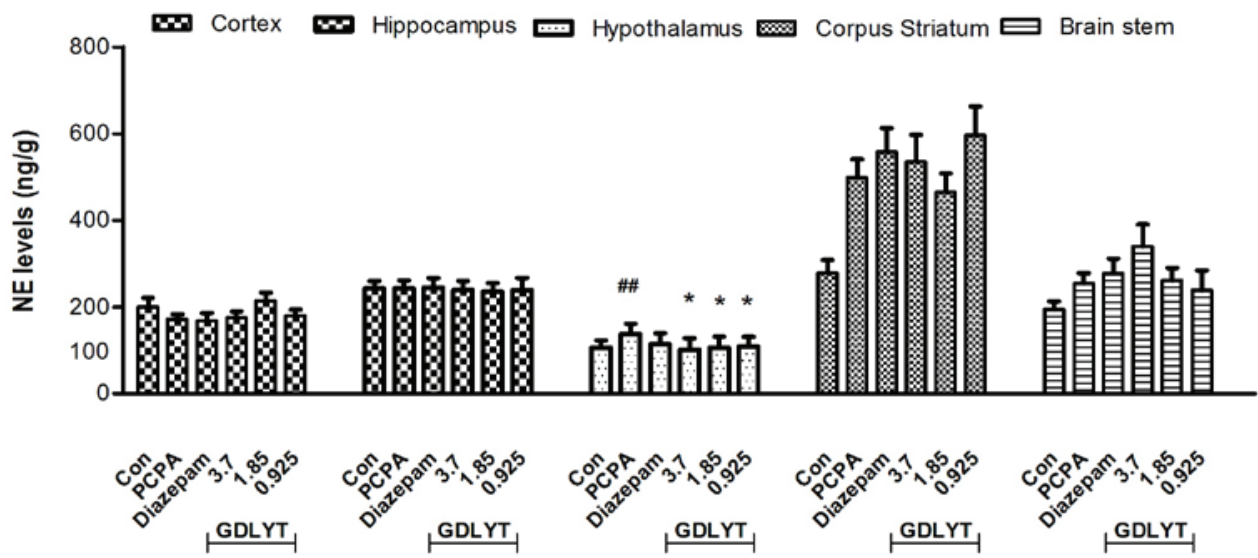

Figure 1. Effect of GDLYT on the concentration of (A) 5-HT and (B) NE in the various brain regions of PCPA-treated mice (n=8). Data are expressed as a mean \pm standard error of the mean. ${ }^{*} \mathrm{P}<0.05$, vs. the control group; ${ }^{*} \mathrm{P}<0.05$ and ${ }^{* *} \mathrm{P}<0.01$, vs. the PCPA group. PCPA, p-chlorophenylalanine; GDLYT, Gan-Dan-Liang-Yi-Tang; 5-HT, 5-hydroxytryptamine.

Effect of GDLYT on monoaminergic neurotransmitter and cytokines in rats. As shown in Fig. 1A, after 7 days treatment, PCPA treatment induced a significant decrease in 5-HT levels $(\mathrm{P}<0.05)$ in several areas of the brain, including the prefrontal cortex, hippocampus, hypothalamus, corpus striatum and brain stem, whereas it only induced an increase in NE levels in the hypothalamus (Fig. 1B). PCPA did not have any effect on DA levels in the brain (data has not shown). GDLYT was able to significantly reverse the effects of PCPA after 7 days administration in the prefrontal cortex, hippocampus, hypothalamus and corpus striatum $(\mathrm{P}<0.05)$, as compared with the PCPA group (Fig. 1A). Furthermore, GDLYT decreased NE levels in the hypothalamus (Fig. 1B) and there were no significant changes in DA levels (data not shown). In addition, a decrease in TNF- $\alpha$ and IL-2 levels and an increase in IL- 6 levels were observed following treatment with PCPA, although IL-4 levels 
Table II. Effect of GDLYT on pentetrazole-induced convulsions and mortality in mice $(n=10)$.

\begin{tabular}{|c|c|c|c|c|c|c|c|}
\hline \multirow[b]{2}{*}{ Group } & \multirow[b]{2}{*}{ Dosage $(\mathrm{g} / \mathrm{kg})$} & \multicolumn{2}{|c|}{3 days (mouse number) } & \multicolumn{2}{|c|}{5 days (mouse number) } & \multicolumn{2}{|c|}{7 days (mouse number) } \\
\hline & & Latency (sec) & Mortality (\%) & Latency (sec) & Mortality (\%) & Latency (sec) & Mortality (\%) \\
\hline Control & - & $57.2 \pm 20.2$ & 90 & $59.7 \pm 17.8$ & 90 & $54.5 \pm 13.3$ & 91 \\
\hline Diazepam & 0.0013 & $128.0 \pm 34.7^{\mathrm{a}}$ & $30^{\mathrm{b}}$ & $129.0 \pm 61.3^{\mathrm{a}}$ & $10^{\mathrm{b}}$ & $80 \pm 15.4^{\mathrm{a}}$ & $16^{\mathrm{b}}$ \\
\hline \multirow[t]{4}{*}{ GDLYT } & 5.2 & $68.6 \pm 22.1$ & 80 & $66.0 \pm 13.6$ & 80 & $57 \pm 13.2$ & 58 \\
\hline & 2.6 & $53.2 \pm 9.6$ & 80 & $131.1 \pm 115.8$ & 70 & $56 \pm 6.5$ & 58 \\
\hline & 1.3 & $55.7 \pm 11.3$ & 60 & $164.6 \pm 108.9^{a}$ & 50 & $89 \pm 16.0^{\mathrm{a}}$ & $36^{a}$ \\
\hline & 0.65 & $57.3 \pm 13.7$ & 70 & $144.9 \pm 123.9$ & 90 & $57 \pm 10.1$ & 75 \\
\hline
\end{tabular}

The latency represents the latency of myoclonic jerks, expressed as mean \pm standard error of the mean. ${ }^{a} \mathrm{P}<0.05$ and ${ }^{b} \mathrm{P}<0.01$, vs. the control group. The data were analyzed by one-way analysis of variance followed by Dunnett's post-hoc test. Mortality was analyzed by $\chi^{2}$ test. GDLYT, Gan-Dan-Liang-Yi-Tang.

Table III. Effect of GDLYT on movement in PCPA-treated rats $(n=8)$.

Total movement distance $(\mathrm{m})$

\begin{tabular}{|c|c|c|c|}
\hline \multirow[b]{2}{*}{ Group } & \multirow[b]{2}{*}{ Dosage $(\mathrm{g} / \mathrm{kg})$} & \\
\hline & & 2-day PCPA treatment & 7-day GDLYT treatment \\
\hline Control & - & $16.786 \pm 5.981$ & $12.915 \pm 2.649$ \\
\hline PCPA & 0.3 & $27.348 \pm 10.235^{\mathrm{a}}$ & $21.791 \pm 7.453^{\mathrm{b}}$ \\
\hline Diazepam & 0.001 & $25.180 \pm 7.002^{\mathrm{a}}$ & $12.694 \pm 1.344^{\mathrm{a}}$ \\
\hline \multirow[t]{3}{*}{ GDLYT } & 3.7 & $24.076 \pm 7.262^{\mathrm{a}}$ & $9.445 \pm 3.296^{\mathrm{c}}$ \\
\hline & 1.85 & $27.421 \pm 9.515^{\mathrm{a}}$ & $9.069 \pm 2.846^{\mathrm{c}}$ \\
\hline & 0.925 & $23.481 \pm 5.989^{\mathrm{a}}$ & $7.648 \pm 2.606^{\mathrm{c}}$ \\
\hline
\end{tabular}

Dates expressed as mean \pm standard error of the mean. ${ }^{b} \mathrm{P}<0.05$, vs. the control group; ${ }^{a} \mathrm{P}<0.05$ and ${ }^{\mathrm{c}} \mathrm{P}<0.01$, vs. the $\mathrm{PCPA}$ group. $\mathrm{PCPA}$, p-chlorophenylalanine; GDLYT, Gan-Dan-Liang-Yi-Tang.

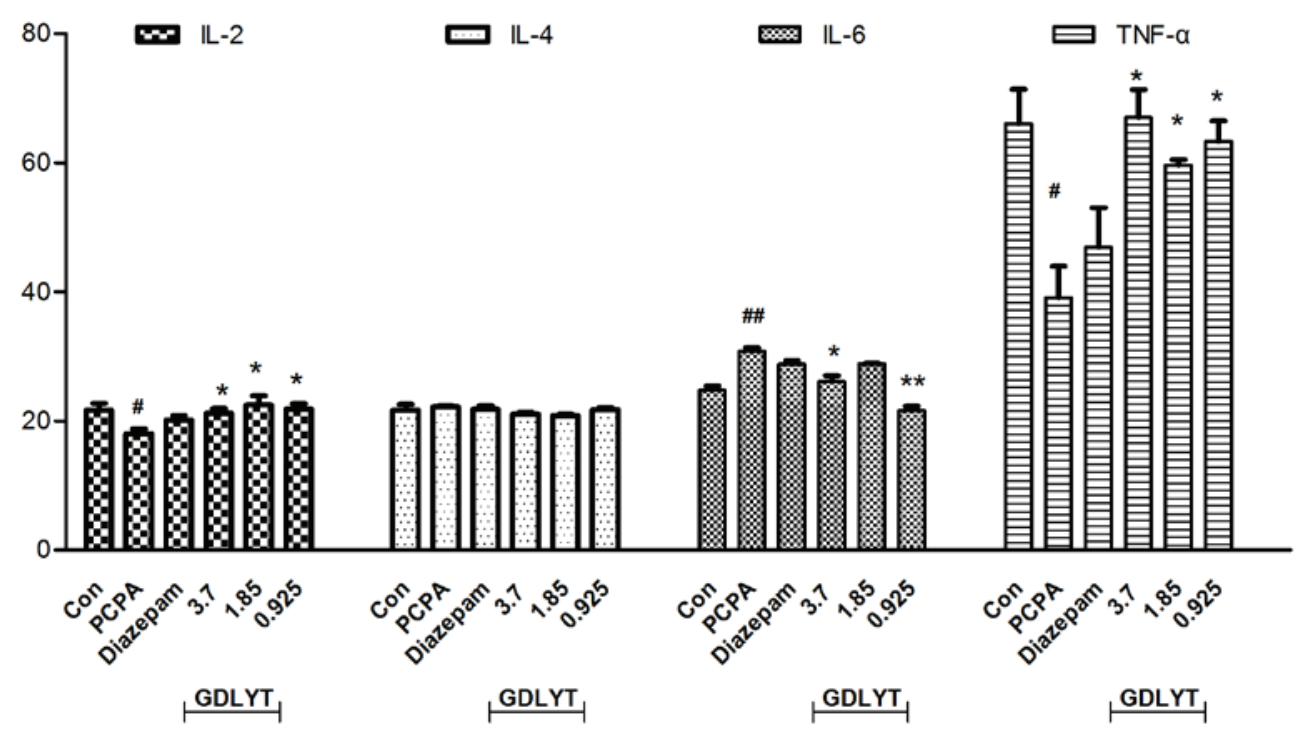

Figure 2. Effect of GDLYT on inflammatory cytokine levels in the PCPA-treated mice. The effect of GDLYT on IL-2, IL-4, IL-6 and TNF- $\alpha$ (n=8). Data are expressed as a mean \pm standard error of the mean. ${ }^{*} \mathrm{P}<0.05$, vs. the control group; ${ }^{*} \mathrm{P}<0.05$ and ${ }^{* *} \mathrm{P}<0.01$, vs. the PCPA group. GDLYT, Gan-Dan-Liang-Yi-Tang; 5-HT, 5-hydroxytryptamine; IL, interleukin; TNF, tumor necrosis factor.

were unaffected (Fig. 2). Following treatment with GDLYT at doses of 3.7, 1.85 and $0.925 \mathrm{~g} / \mathrm{kg}$, TNF- $\alpha$ and IL-2 levels were significantly increased, and those of IL- 6 were significantly decreased, as compared with the PCPA group (P<0.05; Fig. 2). 


\section{Discussion}

Insomnia is an common phenomenon causing both physical and mental health impairments (17). However, evidence for treatment options is limited. Insomnia and anxiety are typically treated with adjunctive benzodiazepines, which risk abuse and dependency if used chronically (18). In the current study, the results demonstrated that a traditional herbal medicine, GDLYT, exerts hypnotic-sedative and anticonvulsant effects in mice.

In the brain, endogenous neurotransmitters such as asdopamine, norepinephrine, acetylcholine, serotonin, GABA, histamine and neuropeptides have been suggested to have important roles in sleep mechanisms (19-22). GDLYT decreased the sleep onset in an animal model treated with a subhypnotic dosage of pentobarbital, a classic behavioral pharmacology methods, shown its hypnotic-sedative effect. As PTZ has been reported to interact with the GABA neurotransmitter $(11,13,23)$, the restrain of PTZ-induced seizures suggests that GDLYT possesses anticonvulsant properties through some of bioactive constituents adjusts GABA-ergic neurotransmission.

In addition, chronic administration of PCPA, a serotonin 5-HT synthesis inhibitor, may induce complete insomnia or substantially reduced sleep (24). These insomnia effects were resisted by treatment with GDLYT, which may involve the restoration of serotonin synthesis and thus restored sleep. Therefore, it was hypothesized that the serotonin system was hypnogenic, due to the serotonin-sleep connection. A previous study demonstrated that when serotonin concentration is decreased or following the destruction of the dorsal raphe nuclei in the brainstem, which contain the majority of the serotonergic cell bodies of the brain, sleep is also reduced (25). As reviewed by Dugovic (26), the complex effects of 5-HT in the adjusting on sleep is in part due to the fact that 5-HT may be present in different areas of the brain that are involved in the control of sleep and wakefulness. Consistent with previous reports, the results of the present study demonstrated that different 5-HT levels could be observed in various areas of the brain. GDLYT was able to reverse PCPA-induced 5-HT decrease in several parts of the brain, including the cortex, hippocampus, striatum and hypothalamus. Furthermore, GDLYT also modulated NE levels in the hypothalamus. These results suggested there may be certain activated components of GDLYT that stimulated the serotonergic system.

Cytokines have an important role in immune activation, but are also transported into the central nervous system, where they influence noradrenergic, dopaminergic and serotonergic neurotransmission (27). IL-1 and IL-6 were reported to be associated with psychomotor, sickness behavior and sleep $(28,29)$; IL-2 and TNF- $\alpha$ partly disturb memory and are involved in cognitive impairment. The hyper-secretion of IL-2 has been associated with schizophrenia, and that of IL-6 with depression $(30,31)$. As observed in the present study, the expression levels of IL- 2 and TNF- $\alpha$ pro-inflammatory cytokines were decreased, and those of IL-6 anti-inflammatory cytokine were increased following treatment with PCPA inhibitor. Treatment with GDLYT increases the expression levels of IL-2 and TNF- $\alpha$, and reduced the serum expression levels of IL-6. Therefore, another important mechanism underlying the effect of GDLYT on sleep disorders in animals is by adjusting cytokine levels so that each can be maintained at normal ranges.

In conclusion, the results of the present study revealed that GDLYT may contain anti-psychoactive components with potential hypnotic, sedative and anticonvulsant properties. The results also suggested that the serotonergic and immune system may participated in the hypnotic-sedative activity of GDLYT. Future studies will be required in order to investigate the mechanism underlying this hypnotic-sedative effect, and to isolate the active ingredient from GDLYT.

\section{Acknowledgements}

The present study was supported by a grant from the National Military Chinese Medicine Special Foundation (grant no. 10ZYZ141).

\section{References}

1. Zhang Gang-qiang HX, Dong Xian-zhe,Liu Ping: Sedative and Hypnotic Activities of Gandan Liangyi Tang via the Elevation Effects on Amino Acids Neurotranmitters in Mice. Zhong Guo Shi Yan Fang Ji Xue Za Zhi 19: 226-229, 2013 (In Chinese).

2. Yao Y, Jia M, Wu JG, Zhang H, Sun LN, Chen WS and Rahman K: Anxiolytic and sedative-hypnotic activities of polygalasaponins from Polygala tenuifolia in mice. Pharm Biol 48: 801-807, 2010.

3. Lee CI, Lee MK and Oh KW: Ethanol extract of Polygalae radix augments pentobarbital-induced sleeping behaviors through GABA(A)ergic systems. Natural Product Sciences 19: 179-185, 2013.

4. Lee SM, Yoon MY and Park HR: Protective effects of Paeonia lactiflora pall on hydrogen peroxide-induced apoptosis in PC12 cells. Biosci Biotechnol Biochem 72: 1272-1277, 2008.

5. Mao QQ, Ip SP, Tsai SH and Che CT: Antidepressant-like effect of peony glycosides in mice. J Ethnopharmacol 119: 272-275, 2008.

6. Zhang MZ,Zhang QY and Cui GB: Clinical study of XiaoYao-San in the treatment of depressive neurosis. Shan Dong Zhong Yi Yao Da Xue Xue Bao 22: 34-37, 1998 (In Chinese).

7. Shen HX, Jiang ZL, Dong GS, Yang HQ, Jiang R, Li X, Yin P and Chen MM: Anti-motion sickness efficacy of the extracted mixture of Chinese medical herbs and its influence on the blood level of hormones. Zhongguo Ying Yong Sheng Li Xue Za Zhi 28: 398-403, 2012 (In Chinese).

8. TingLi WWSWL: The antidepression effect of ChaoZaiRen. Zhong Yi Yao Xue Bao 42: 13-15, 2014 (In Chinese).

9. Xing-li H: Peng's gouqizaoren decoction intractable insomnia treatment. Shi Yong Zhong Yi Nei Ke Za Zhi 6: 58-59, 2010 (In Chinese).

10. Shi Y, Dong JW, Zhao JH, Tang LN and Zhang JJ: Herbal insomnia medications that target GABAergic systems: A review of the psychopharmacological evidence. Curr Neuropharmacol 12: 289-302, 2014.

11. Cao JX, Zhang QY, Cui SY, Cui XY, Zhang J, Zhang YH, Bai YJ and Zhao YY: Hypnotic effect of jujubosides from Semen Ziziphi Spinosae. J Ethnopharmacol 130: 163-166, 2010.

12. Zhao X, Cui XY, Chen BQ, Chu QP, Yao HY, Ku BS and Zhang YH: Tetrandrine, a bisbenzylisoquinoline alkaloid from Chinese herb radix, augmented the hypnotic effect of pentobarbital through serotonergic system. Eur J Pharmacol 506: 101-105, 2004.

13. Chindo BA, Ya'U J, Danjuma NM, Okhale SE, Gamaniel KS and Becker A: Behavioral and anticonvulsant effects of the standardized extract of Ficus platyphylla stem bark. J Ethnopharmacol 154: 351-390, 2014.

14. Ngo Bum E, Taiwe GS, Moto FC, Ngoupaye GT, Nkantchoua GC, Pelanken MM, Rakotonirina SV and Rakotonirina A: Anticonvulsant, anxiolytic and sedative properties of the roots of Nauclea latifolia smith in mice. Epilepsy Behav 15: 434-440, 2009.

15. Malhi SM, Jawed H, Hanif F, Ashraf N, Zubair F, Siddiqui BS, Begum S, Kabir N and Simjee S: Modulation of c-Fos and BDNF protein expression in pentylenetetrazole-kindled mice following the treatment with novel antiepileptic compound HHL-6. Biomed Res Int 2014: 876712, 2014 
16. Hu Y, Liu P, Dai-Hong G, Rahman K, Wang DX, Chen ML and Xie TT: Behavioral and biochemical effects of Kaixin-San, a traditional Chinese medicinal empirical formula. Drug Dev Res 69: 267-271, 2008.

17. Putnins SI, Griffin ML, Fitzmaurice GM, Dodd DR and Weiss RD: Poor sleep at baseline predicts worse mood outcomes in patients with co-occurring bipolar disorder and substance dependence. J Clin Psychiatry 73: 703-708, 2012.

18. Uzun S, Kozumplik O, Jakovljević M and Sedić B: Side effects of treatment with benzodiazepines. Psychiatria Danubina 22: 90-93, 2010.

19. Karmann AJ, Kundermann B and Lautenbacher S: Sleep deprivation and pain: A review of the newest literature. Schmerz 28: 141-146, 2014 (In German).

20. Monti JM, BaHammam AS, Pandi-Perumal SR, Bromundt V Spence DW, Cardinali DP and Brown GM: Sleep and circadian rhythm dysregulation in schizophrenia. Prog Neuropsychopharmacol Biol Psychiatry 43: 209-216, 2013.

21. Roecker AJ, Mercer SP, Schreier JD, Cox CD, Fraley ME, Steen JT, Lemaire W, Bruno JG, Harrell CM, Garson SL, et al: Discovery of 5'-chloro-N-[(5,6-dimethoxypyridin-2-yl) methyl]-2,2':5',3'-terpyridine-3'-carboxamide (MK-1064): A selective orexin 2 receptor antagonist (2-SORA) for the treatment of insomnia. Chem Med Chem 9: 311-322, 2014.

22. van Swinderen B and Kottler B: Explaining general anesthesia: A two-step hypothesis linking sleep circuits and the synaptic release machinery. Bioessays 36: 372-381, 2014.

23. Salih MA and Mustafa AA: A substance in broad bean (Vicia faba) is protective against experimentally induced convulsions in mice. Epilepsy Behav 12: 25-29, 2008.
24. Borbély AA, Neuhaus HU and Tobler I: Effect of p-chlorophenylalanine and tryptophan on sleep, EEG and motor activity in the rat. Behav Brain Res 2: 1-22, 1981.

25. Gianotti M, Botta M, Brough S, Carletti R, Castiglioni E, Corti C, Dal-Cin M, Delle Fratte S, Korajac D, Lovric M, et al: Novel spirotetracyclic zwitterionic dual H-1/5-HT2A receptor antagonists for the treatment of sleep disorders. J Med Chem 53: 7778-7795, 2010.

26. Dugovic C: Role of serotonin in sleep mechanisms. Rev Neurol (Paris) 157: S16-S19, 2001.

27. Ruiz FS, Andersen ML, Martins RC, Zager A, Lopes JD and Tufik S: Immune alterations after selective rapid eye movement or total sleep deprivation in healthy male volunteers. Innate Immunity 18: 44-54, 2012.

28. Zhao Q, Peng C, Wu X, Chen Y, Wang C and You Z: Maternal sleep deprivation inhibits hippocampal neurogenesis associated with inflammatory response in young offspring rats. Neurobiol Dis 68: 57-65, 2014.

29. Müller N: Role of the cytokine network in the CNS and psychic disorders. Nervenarzt 68: 11-20, 1997 (In German).

30. Patterson ZR and Holahan MR: Understanding the neuroinflammatory response following concussion to develop treatment strategies. Front Cell Neurosci 6: 58, 2012.

31. Torabi-Nami M, Nasehi M and Zarrindast M-R: Sleep loss and the brain vulnerability to neurodegeneration: Behavioral, biochemical and neuro-histopathological observations in a rat model. Excli Journal 12: 347-372, 2013. 